Check for updates

Cite this: RSC Adv., 2018, 8, 40219

Received 30th August 2018

Accepted 9th November 2018

DOI: $10.1039 / \mathrm{c} 8 \mathrm{ra} 07255 \mathrm{~h}$

rsc.li/rsc-advances

\section{The potential use of thermosensitive chitosan/silk sericin hydrogels loaded with longan seed extract for bone tissue engineering $\dagger$}

\begin{abstract}
Porntipa Pankongadisak ${ }^{\mathrm{ab}}$ and Orawan Suwantong (iD *ab
In this study, hydrogels that were thermosensitive at body temperature were developed using chitosan (CS)/ silk sericin (SS)/ $\beta$-glycerophosphate ( $\beta$-GP) loaded with longan seed extract (LE) for use in bone tissue engineering. These hydrogels were transformed into a gel at $37{ }^{\circ} \mathrm{C}$ within $10 \mathrm{~min}$ via interactions between CS and $\beta$-GP. The incorporation of SS resulted in a shorter gelation time of 5-7 min. The morphological structure of the thermosensitive CS/ $\beta$-GP hydrogels exhibited an irregular pore structure, whereas the morphological structure of the thermosensitive CS/SS/ $\beta$-GP hydrogels became more slender and porous. The incorporation of SS affected the network structure of the CS hydrogels, which degraded more rapidly. Moreover, the cumulative amounts of both gallic acid (GA) and ellagic acid (EA) released from the hydrogels loaded with LE increased with an increase in the SS content. Finally, these thermosensitive hydrogels were non-toxic to both a mouse fibroblast cell line (NCTC clone 929) and a mouse osteoblast cell line (MC3T3-E1) and promoted the attachment of MC3T3-E1 cells to the surface of the hydrogels. Therefore, these thermosensitive hydrogels might be a promising candidate for bone tissue engineering.
\end{abstract}

\section{Introduction}

Thermosensitive hydrogels are materials that are in the liquid form for a desired period of time below or at room temperature and turn into a gel at physiological or body temperature after a few minutes. ${ }^{1}$ Thermosensitive hydrogels have aroused a great deal of interest in various applications (e.g., drug delivery, ${ }^{2}$ tissue engineering, ${ }^{3}$ cell encapsulation, ${ }^{4}$ etc.). Such thermosensitive hydrogel systems may provide several advantages over conventional hydrogels for drug delivery systems, including protection of the drug from the environment and prolongation of drug release. Besides, their initial liquid formulations can flow to the target site without a surgical procedure for placing and filling a defect by virtue of their fluidity to exactly fit the interior space. ${ }^{5}$ Hence, the operational performance requirements for implantation are not necessary.

Chitosan (CS)-based materials have been used in the medical and pharmaceutical fields as biomaterials in the development of targeted and controlled drug delivery because of their biodegradability, biocompatibility, non-toxicity, low immunogenicity, antibacterial nature, and good cell adhesion. ${ }^{6,7} \beta$ -

${ }^{a}$ School of Science, Mae Fah Luang University, Tasud, Muang, Chiang Rai 57100, Thailand. E-mail: o.suwantong@gmail.com; Fax: +66-5391-6776; Tel: +66-5391-6787 ${ }^{b}$ Center for Chemical Innovation for Sustainability (CIS), Mae Fah Luang University, Tasud, Muang, Chiang Rai 57100, Thailand

$\dagger$ Electronic supplementary information (ESI) available. See DOI: 10.1039/c8ra07255h
Glycerophosphate ( $\beta$-GP) has been used as a catalyst for achieving a sol-to-gel transition in CS solutions at a physiological temperature or $37{ }^{\circ} \mathrm{C}^{3}$ In addition, thermosensitive chitosan/ $\beta$-glycerophosphate (CS/ $\beta$-GP) hydrogels have been utilized as an intelligent drug delivery system to improve patient compliance by maintaining the range of doses of therapeutic drugs for a long time while avoiding the requirement for frequent injections of therapeutic drugs. ${ }^{8}$

Currently, silk sericin (SS) has received increasing attention as an alternative option in bone tissue engineering owing to its environmentally friendly, renewable and non-toxic properties. It has several biological advantages, such as low immunogenicity, biodegradability, and excellent biocompatibility. ${ }^{9}$ Moreover, it has antioxidant activities, ${ }^{\mathbf{1 0}}$ antibacterial activities, ${ }^{\mathbf{1 1}}$ and anticoagulation activities ${ }^{\mathbf{1 2}}$ and can promote cell growth and differentiation..$^{13}$ Hence, it has become an attractive option as a biomaterial in the field of regenerative medicine. However, it was blended with other polymers to improve their properties for use in biomedical applications. ${ }^{\mathbf{1 4}}$ Therefore, SS could be used as an additional component to enhance the thermogelling property and biocompatibility of thermosensitive hydrogels.

The longan, or Dimocarpus longan Lour. (syn. Euphoria longana Lam.), is a semitropical fruit that is widely cultivated in Northern Thailand and is called "Lamyai" in Thailand. ${ }^{\mathbf{1 5}}$ Longan seeds contain large amounts of polyphenolic compounds such as corilagin, gallic acid (GA), and ellagic acid (EA),${ }^{16}$ but the pulp and peel contain small amounts of polyphenolic compounds. GA and EA have been used in several 
studies to promote their health benefits owing to their antimicrobial, antioxidant and anti-inflammatory activities. ${ }^{17}$ Besides, it has been reported that EA can be used to prevent alveolar bone loss and accelerate the formation of new bone after teeth are extracted. ${ }^{18}$

In this study, novel thermosensitive hydrogels based on chitosan (CS) and silk sericin (SS) and loaded with longan seed extract (LE) as a model drug were developed to achieve a balance between the thermogelling property and biocompatibility for use in bone tissue engineering. It was hypothesized that a system based on a combination of CS and SS could form a sol at room temperature and be transformed rapidly into a gel state at physiological temperature. The properties of these thermosensitive hydrogels, including molecular structures, rheological behavior, and morphological characteristics, were characterized using Fourier transform infrared (FTIR) spectroscopy, rheometry, and scanning electron microscopy (SEM), respectively. Furthermore, the degradability, profiles of the in vitro release of both GA and EA from the hydrogels, cytotoxicity, and cell morphology were studied to investigate the potential use of these materials in bone tissue engineering.

\section{Experimental}

\subsection{Materials}

CS derived from snow crab shells/Alaska crab shells (viscosity $=$ 600-900 cps, degree of deacetylation $\geq 95 \%$ ) was purchased from Bio 21 Co., Ltd (Chonburi, Thailand). Raw silk cocoons from the mulberry silkworm Bombyx mori were obtained from the Queen Sirikit Sericulture Center (Chiang Mai, Thailand). $\beta$ Glycerophosphate disodium salt hydrate, GA, EA, glycine, and 2,2-diphenyl-1-picrylhydrazyl (DPPH) were purchased from Sigma-Aldrich (USA). L-Ascorbic acid was purchased from Chem-Supply Pty Ltd (Australia). Anhydrous sodium carbonate $\left(\mathrm{Na}_{2} \mathrm{CO}_{3}\right)$, sodium chloride $(\mathrm{NaCl})$, anhydrous disodium hydrogen orthophosphate $\left(\mathrm{Na}_{2} \mathrm{HPO}_{4}\right)$, potassium chloride $(\mathrm{KCl})$, and monopotassium phosphate $\left(\mathrm{KH}_{2} \mathrm{PO}_{4}\right)$ were purchased from Ajax Chemicals (Australia). Alpha-amylase was purchased from HiMedia Laboratories (India). Ethanol, methanol, and dimethyl sulfoxide (DMSO) were purchased from RCI LabScan Limited (Bangkok, Thailand). Glacial acetic acid was purchased from Merck KGaA (Germany). All chemicals were of analytical reagent grade and were used without further purification.

\subsection{Extraction of longan seed}

The longan cultivar Edor (Dimocarpus longan Lour.) was used in this study. Edor is a commercial cultivar available in Northern Thailand. Fresh longan fruit were obtained from a longan farm in Lamphun province, Thailand. Longan seed was used for extraction because it contains large amounts of GA and EA. Longan seed extract (LE) was extracted using an organic solvent. Firstly, $200 \mathrm{mg}$ of dried ground longan seed was accurately weighed and extracted three times with $50 \mathrm{~mL}$ of mixtures with different fractions of water and ethanol $(100: 0,70: 30,50: 50$, $30: 70$, and $0: 100)$ at room temperature for 3 days. The extracts from each extraction process were then combined and filtered through filter paper. After that, ethanol was evaporated from each extract, which was dried using a freeze-drying method. Finally, the percentage yield of each fraction of LE was calculated.

LE from each fraction was analyzed to determine the contents of polyphenolic compounds (i.e., GA and EA) using a Waters 600E high-performance liquid chromatography (HPLC) system. Separation was performed with an Alltech Prevail C18 column $(250 \mathrm{~mm} \times 4.6 \mathrm{~mm}, 5 \mu \mathrm{m})$, and the temperature of the column was set at $25{ }^{\circ} \mathrm{C}$. The mobile phase consisted of $0.1 \%(\mathrm{v} / \mathrm{v})$ formic acid in water (solvent $\mathrm{A}$ ) and methanol (solvent B) for gradient elution (0 min, $96: 4 ; 27 \mathrm{~min}$, $20: 80 ; 28 \mathrm{~min}, 96: 4$ and $33 \mathrm{~min}, 96: 4$ ) with a total run time of $33 \mathrm{~min}$ at a flow rate of $1.0 \mathrm{~mL} \mathrm{~min}{ }^{-1}$. The sample injection volume was $10 \mu \mathrm{L}$. The detection of polyphenolic compounds was achieved using a UV-vis spectrophotometer with a diode array detector at $270 \mathrm{~nm}$. Standard solutions with seven concentrations $(25,50,100,150,200,250$, and $300 \mathrm{ppm})$ of GA and EA were injected, and then a calibration curve was obtained by plotting the peak area against the concentration of each sample. Moreover, the antioxidant activity and cytotoxicity of LE were determined using a 2,2-diphenyl-1-picrylhydrazyl (DPPH) radical scavenging assay and a resazurin microplate assay (REMA), respectively, as shown in the ESI. $\dagger$

\subsection{Preparation of thermosensitive chitosan/ $\beta$-glycerophosphate (CS/ $\beta$-GP) hydrogels}

Firstly, the optimal conditions for preparing the thermosensitive CS/ $\beta$-GP hydrogels were identified. CS solutions with various concentrations $(3.0,3.5$, and $4.0 \%, \mathrm{w} / \mathrm{v})$ were prepared by dissolving CS powder in an aqueous acetic acid solution $(1 \%$, $\mathrm{v} / \mathrm{v})$. The CS solutions were stirred well to give a homogeneous solution at room temperature. In addition, a $50 \%(\mathrm{w} / \mathrm{v})$ solution of $\beta$-GP was prepared by dissolving $\beta$-GP powder in deionized water. The CS and $\beta$-GP solutions were cooled to $4{ }^{\circ} \mathrm{C}$ using an ice bath for $15 \mathrm{~min}$. Then, the $50 \%(\mathrm{w} / \mathrm{v})$ solution of $\beta$-GP was added dropwise to the CS solution under stirring for $20 \mathrm{~min}$ with various volume ratios of CS to $\beta$-GP $(0.7: 0.3,0.5: 0.5$, and $0.3: 0.7 \mathrm{~mL}$ ).

The $\mathrm{pH}$ of the solution prepared in each set of conditions was measured to ensure a physiologically acceptable neutral solution at room temperature using a Eutech Cyberscan pH 510 meter (Thermo Scientific, Germany) before the determination of the gelation time. The freshly prepared thermosensitive $\mathrm{CS} / \beta$ GP hydrogels were examined by a simple test tube inversion method. A $1 \mathrm{~mL}$ sample of the solution was added to a vial in a temperature-controlled bath at $37{ }^{\circ} \mathrm{C}$. In order to observe whether the solution had undergone gelation, the vial was inverted horizontally, and the gelation time was defined as the time at which the solution no longer flowed.

\subsection{Preparation of silk sericin and thermosensitive chitosan/ silk sericin/ $\beta$-glycerophosphate (CS/SS/ $\beta$-GP) hydrogels}

Raw Thai silk cocoons from B. mori silkworms were cut into small pieces and degummed with $0.5 \%(\mathrm{w} / \mathrm{v})$ sodium carbonate 
$\left(\mathrm{Na}_{2} \mathrm{CO}_{3}\right)$ at $85{ }^{\circ} \mathrm{C}$ for $45 \mathrm{~min}$. The aqueous solution obtained from boiling silk cocoons was collected and was denoted as silk sericin (SS). This aqueous solution was then filtered to remove insoluble materials (or degummed silk fibers). The SS solution was dialyzed in deionized water for 3 days using a cellulose membrane (Cellu-Sep ${ }^{\circledR}$ T4, nominal MWCO: 12 000-14 000), and the deionized water was replaced every $12 \mathrm{~h}$ to remove salts. Lipids and impurities were removed from the SS solution by centrifugation at $3500 \mathrm{rpm}$ at $25{ }^{\circ} \mathrm{C}$ for $20 \mathrm{~min}$. Finally, the SS solution was lyophilized using a freeze-drying method at $-40{ }^{\circ} \mathrm{C}$ for $19 \mathrm{~h}$.

Thermosensitive CS/SS/ $\beta$-GP hydrogels were prepared with a fixed concentration of CS $(3.5 \%, \mathrm{w} / \mathrm{v})$ and SS solutions with various concentrations $(1.5,2.5$ and $3.5 \%, \mathrm{w} / \mathrm{v})$. The incorporation of SS into the CS solution was chosen to examine its effect on the gelation time of the modified hydrogels. Firstly, a 3.5\% $(\mathrm{w} / \mathrm{v})$ solution of CS was prepared by dissolving CS powder in an aqueous acetic acid solution $(1 \%, \mathrm{v} / \mathrm{v})$. Then, $1.5,2.5$, and $3.5 \%$ $(\mathrm{w} / \mathrm{v})$ solutions of SS were prepared by dissolving SS powder in deionized water. The mixture of CS and SS solutions prepared in each set of conditions was well stirred to give a homogeneous solution at room temperature. A $50 \%(\mathrm{w} / \mathrm{v})$ solution of $\beta$-GP was prepared by dissolving $\beta$-GP powder in deionized water. After that, all the solutions were cooled to $4{ }^{\circ} \mathrm{C}$ using an ice bath for $15 \mathrm{~min}$. Then, the $50 \%(\mathrm{w} / \mathrm{v})$ solution of $\beta$-GP was added dropwise to the mixture of CS and SS solutions under stirring for $20 \mathrm{~min}$ with a volume ratio of the CS/SS mixture to the $\beta$-GP solution that was equal to $0.5: 0.5 \mathrm{~mL}$.

The $\mathrm{pH}$ of the solution prepared in each set of conditions was measured to ensure a physiologically acceptable neutral solution at room temperature using a $\mathrm{pH}$ meter before the determination of the gelation time. Then, the freshly prepared thermoresponsive hydrogels were examined by a simple test tube inversion method according to the previous test procedure.

\subsection{Rheological and viscosity measurements}

Rheological measurements of the thermosensitive CS/ $\beta$-GP and CS/SS/ $\beta$-GP hydrogels were carried out using a Bohlin Gemini 200HR nano-rotational rheometer (Malvern, UK) equipped with a parallel geometry with a diameter of $40 \mathrm{~mm}$, and the gap was set to $1 \mathrm{~mm}$. A $1 \mathrm{~mL}$ sample of the solutions was placed on top of the rheometer and equilibrated at $20{ }^{\circ} \mathrm{C}$ for $4 \mathrm{~min}$. During the gelation process, the rheological properties of samples were measured within the temperature range of $20{ }^{\circ} \mathrm{C}$ to $50{ }^{\circ} \mathrm{C}$ at a heating rate of $2{ }^{\circ} \mathrm{C} \mathrm{min}{ }^{-1}$ and a frequency of $3 \mathrm{~Hz}$. Changes in the elastic (storage) modulus $\left(G^{\prime}\right)$ and the viscous (loss) modulus $\left(G^{\prime \prime}\right)$ were recorded as a function of temperature.

The sol-gel transition behavior of the thermosensitive $\mathrm{CS} / \beta$ $\mathrm{GP}$ and $\mathrm{CS} / \mathrm{SS} / \beta$-GP hydrogels was investigated in terms of the viscosity of the hydrogels using a Bohlin Gemini 200HR nanorotational rheometer (Malvern, UK) within the temperature range of $20-50{ }^{\circ} \mathrm{C}$.

\subsection{Chemical structure and morphological study}

The thermosensitive CS/ $\beta$-GP and CS/SS/ $\beta$-GP hydrogels were incubated in a water bath at $37{ }^{\circ} \mathrm{C}$ prior to being observed.
When the hydrogels were transformed into gels, the gels were frozen at $-40{ }^{\circ} \mathrm{C}$ for $24 \mathrm{~h}$ and then lyophilized by a freeze-drying method for $19 \mathrm{~h}$. A sample and potassium bromide were ground into a homogeneous fine powder and then pressed into a disc. Measurements were carried out in the range of $4000-700 \mathrm{~cm}^{-1}$ with a resolution of $4 \mathrm{~cm}^{-1}$ using a Spectrum GX Fourier transform infrared spectrometer (PerkinElmer, USA).

The surface of the freeze-dried hydrogels was then coated with a thin layer of gold under vacuum, and the morphology was observed using a LEO 1450 VP scanning electron microscope (Carl Zeiss, Germany) with an accelerating voltage of $10 \mathrm{kV}$.

\subsection{Weight loss}

The weight loss behavior of the thermosensitive CS/ $\beta$-GP and $\mathrm{CS} / \mathrm{SS} / \beta$-GP hydrogels was examined by an immersion method under simulated physiological conditions. A $1 \mathrm{~mL}$ sample of each thermosensitive hydrogel was formed under incubation at $37{ }^{\circ} \mathrm{C}$ for $3 \mathrm{~h}$. Each hydrogel was cut into small pieces of about $5 \mathrm{~mm} \times 5 \mathrm{~mm}$ and then weighed $\left(W_{\mathrm{i}}\right)$ and immersed in $2 \mathrm{~mL}$ of phosphate-buffered saline (PBS) ( $\mathrm{pH}$ 7.4). After that, each sample was incubated at $37^{\circ} \mathrm{C}$ under continuous shaking. At predetermined time intervals (1, 3, 5, 7 and 10 days), the sample was carefully removed from the medium and weighed $\left(W_{\mathrm{t}}\right)$ after being dried. The weight loss percentage ( $W \%$ ) of the hydrogels was calculated according to the following equation:

$$
\text { Weight loss }\left(W^{\circ} \%\right)=\frac{W_{\mathrm{i}}-W_{\mathrm{t}}}{W_{\mathrm{i}}} \times 100
$$

\subsection{In vitro degradation}

The in vitro degradation of the thermosensitive CS/ $\beta$-GP and CS/ SS/ $\beta$-GP hydrogels was examined by an immersion method under simulated physiological conditions. A $1 \mathrm{~mL}$ sample of each thermosensitive hydrogel was formed under incubation at $37{ }^{\circ} \mathrm{C}$ for $3 \mathrm{~h}$ and then immersed in $6 \mathrm{~mL}$ of either PBS ( $\mathrm{pH} 7.4$ ) or PBS ( $\mathrm{pH}$ 6.8) containing $\alpha$-amylase. After that, each sample was incubated at $37{ }^{\circ} \mathrm{C}$ under continuous shaking. At predetermined time intervals (1, 3, 5, 7, and 10 days), $1 \mathrm{~mL}$ of the medium after the sample was immersed was carefully withdrawn and the same amount of fresh medium was added. A ninhydrin assay was used to determine the number of free amino groups in the released medium. Glycine was used as a standard amino acid. After incubation with ninhydrin reagent at $95{ }^{\circ} \mathrm{C}$ for $10 \mathrm{~min}$, the solution was left to cool and an ethanol solution was then added as a stabilizing solvent. Finally, the absorbance of the solution at $570 \mathrm{~nm}$ was measured using a Lambda 35 UV-vis spectrophotometer (PerkinElmer, USA).

\subsection{In vitro release of longan seed extract}

LE, as a model compound, was dissolved in deionized water. Firstly, $5 \mathrm{~mL}$ of each $\mathrm{CS} / \beta$-GP or $\mathrm{CS} / \mathrm{SS} / \beta$-GP solution was mixed with an LE solution $\left(0.5 \mathrm{mg} \mathrm{mL}^{-1}\right)$ to form a homogeneous solution. Then, $1 \mathrm{~mL}$ of each hydrogel loaded with LE was placed in a tube and incubated at $37^{\circ} \mathrm{C}$ to form a gel. After that, 
$6 \mathrm{~mL}$ of PBS (pH 7.4) was added to a tube. All samples were incubated at $37{ }^{\circ} \mathrm{C}$ under continuous shaking. At predetermined time intervals, $1 \mathrm{~mL}$ of the released medium was removed and stored at $4{ }^{\circ} \mathrm{C}$ until analyzed and was immediately replaced with fresh medium to maintain a constant volume. Finally, the cumulative released amounts of both GA and EA as a function of time were determined using a UV-vis spectrophotometer and calculated by constructing a calibration curve of the absorbance versus the concentration of the compounds from 0 to $100 \mathrm{mg} \mathrm{L}^{-1}$.

\subsection{In vitro cytotoxicity and cell morphology}

An indirect evaluation of the cytotoxicity of the thermosensitive $\mathrm{CS} / \beta$-GP and CS/SS/ $\beta$-GP hydrogels loaded with LE was performed using NCTC clone $929\left(22^{\text {nd }}\right.$ passage $)$ or MC3T3-E1 ( $4^{\text {th }}$ passage) cells. The NCTC clone 929 cells were obtained from mouse areolar fibroblasts (ATCC $\AA$ CCL-1 ${ }^{\mathrm{TM}}$ ), whereas the preosteoblasts (MC3T3-E1 cells) were obtained from normal mouse subclone 4 cells (ATCC ${ }^{\circledR}$ CRL-2593 ${ }^{\mathrm{TM}}$ ). The hydrogels were first incubated at $37^{\circ} \mathrm{C}$ for $3 \mathrm{~h}$ and then immersed in serum-free medium (SFM) containing Dulbecco's modified Eagle medium (DMEM; Gibco, USA) or minimum essential medium (MEM; Gibco, USA) and a $1 \%$ antibiotic-antimycotic formulation (Gibco, USA) for an incubation period of $24 \mathrm{~h}$ to produce extraction media with various concentrations $(5,10$, and $50 \mathrm{mg}$ $\mathrm{mL}^{-1}$ ). Before testing, the extraction media were sterilized using $0.22 \mu \mathrm{m}$ Minisart syringe filters (Sartorius, Germany). NCTC clone 929 and MC3T3-E1 cells were separately cultured in wells of a 96-well TCPS plate (SPL Life Science, Korea) at 8000 cells per well in DMEM or MEM for $24 \mathrm{~h}$ to enable cell attachment. The cells were then starved with SFM for $12 \mathrm{~h}$. After that, the medium was replaced with the extraction medium and the cells were re-incubated for $24 \mathrm{~h}$. The viability of the cells cultured with each extraction medium was finally determined by a 3-(4,5dimethylthiazol-2-yl)-2,5-diphenyltetrazolium bromide (MTT) assay (see ESI $\dagger$ ). The viability of cells cultured with fresh SFM was used as a control.

The cell morphology on the hydrogels was observed with a LEO 1450 VP scanning electron microscope (Carl Zeiss, Germany). Firstly, the thermosensitive CS/ $\beta$-GP and CS/SS/ $\beta-G P$ hydrogels loaded with LE and without LE were incubated at $37^{\circ} \mathrm{C}$ for $3 \mathrm{~h}$ and then sterilized under UV radiation for $1 \mathrm{~h}$. MC3T3-E1 ( $4^{\text {th }}$ passage) cells were seeded onto the hydrogels at a density of $3 \times 10^{4}$ cells per well and then cultured in a 24-well TCPS plate (SPL Life Science, Korea) for $24 \mathrm{~h}$ to enable cell attachment. After $24 \mathrm{~h}$, the culture medium in each well plate was removed and each sample was washed with PBS twice. The cells cultured on the samples were then fixed with $3 \%(\mathrm{v} / \mathrm{v})$ glutaraldehyde (Sigma-Aldrich, USA) for $30 \mathrm{~min}$ before dehydration. Dehydration of the samples was performed by a graded series of ethanol concentrations $(30,50,70,90$, and $100 \%, \mathrm{v} / \mathrm{v})$ for $\sim 2$ min each. The samples were immersed in $100 \%$ hexamethyldisilazane (HMDS; Sigma-Aldrich, USA) for $\sim 5 \mathrm{~min}$ and then dried in air after the removal of HMDS at room temperature for $24 \mathrm{~h}$. Finally, the samples were mounted on SEM stubs and coated with gold before SEM observations were performed.

\subsection{Statistical analysis}

The results were presented as the mean \pm standard error of mean. Statistical analysis was carried out by one-way analysis of variance (one-way ANOVA) and Tukey's test in SPSS (IBM SPSS, USA). Statistical significance was accepted at a value of $p<0.05$.

\section{Results and discussion}

\subsection{Longan seed extraction}

Rangkadilok et al. ${ }^{15}$ and Soong et al. ${ }^{16}$ reported that higher contents of polyphenolic compounds (such as corilagin, GA, and EA) were found in the seeds than in the fruit or pulp of longan. Hence, in this study longan seeds were used to extract polyphenolic compounds. Different fractions of water and ethanol were used to extract polyphenolic compounds in seeds of the longan cultivar Edor. Table 1 shows the percentage yields of LE and the contents of GA and EA in LE produced using different fractions of water and ethanol. The results show that the percentage yields of LE produced using different fractions of water and ethanol were $\sim 26-56 \%$. The amounts of GA in LE from different fractions were $\sim 4-13 \mathrm{mg} \mathrm{g}^{-1}$, whereas the amounts of EA were $\sim 15-26 \mathrm{mg} \mathrm{g}^{-1}$. However, the amounts of GA $\left(\sim 13 \mathrm{mg} \mathrm{g}^{-1}\right)$ and EA $\left(\sim 26 \mathrm{mg} \mathrm{g}^{-1}\right)$ produced by solvent extraction using a water to ethanol ratio of $100: 0$ were the highest in comparison with the other fractions. Hence, LE produced by solvent extraction using a water to ethanol ratio of 100 : 0 was selected for further study and used for loading into the thermosensitive hydrogels as a model drug.

\subsection{Determination of antioxidant activity and cytotoxicity of longan seed extract}

The polyphenolic compounds (e.g., GA and EA) in LE are known to have the most powerful antioxidant properties because of their free radical scavenging activity and their specific chemical structure. ${ }^{19}$ In this study, a DPPH ${ }^{\cdot}$ radical scavenging assay was used to measure the antioxidant activity of $\mathrm{LE}^{\mathrm{DPPH}} \mathrm{DP}^{\bullet}$ radicals were converted into DPPH-H (diphenylpicrylhydrazine) molecules in the presence of the antioxidant compounds that were found in LE by the donation of an electron or a hydrogen atom. When the antioxidant compounds were combined with a DPPH solution, the color was changed from the purple color of DPPH ${ }^{*}$ radicals to pale yellow owing to the disappearance of $\mathrm{DPPH}^{*}$ radicals. The absorption maximum of $\mathrm{DPPH}^{\cdot}$ radicals in methanol was measured with a spectrophotometer at $517 \mathrm{~nm}$. It has been reported that a decrease in the absorbance of $\mathrm{DPPH}^{\circ}$

Table 1 Percentage yields of LE and contents of GA and EA in LE produced using mixtures with different fractions of water and ethanol

\begin{tabular}{lllll}
\hline Extraction solvent & $\begin{array}{l}\text { Weight of } \\
\text { extract }(\mathrm{g})\end{array}$ & \% yield & $\begin{array}{l}\text { GA } \\
\left(\mathrm{mg} \mathrm{g}^{-1}\right)\end{array}$ & $\begin{array}{l}\text { EA } \\
\left(\mathrm{mg} \mathrm{g}^{-1}\right)\end{array}$ \\
\hline Water : ethanol $(100: 0)$ & 0.0519 & 25.95 & 13.19 & 26.13 \\
Water : ethanol $(70: 30)$ & 0.1120 & 56.00 & 9.47 & 25.94 \\
Water : ethanol $(50: 50)$ & 0.0968 & 48.40 & 7.05 & 15.27 \\
Water : ethanol $(30: 70)$ & 0.1047 & 52.35 & 6.16 & 21.68 \\
Water : ethanol $(0: 100)$ & 0.0928 & 46.40 & 3.62 & 18.52
\end{tabular}


radicals is caused by antioxidant compounds. ${ }^{20}$ The antioxidant activities of LE in various concentrations $\left(5-2500 \mu \mathrm{g} \mathrm{mL} \mathrm{m}^{-1}\right)$ and ascorbic acid are shown in ESI Fig. S1. $\dagger$ The results show that the percentage antioxidant activity of LE increased from approximately $26 \%$ to $86 \%$ with an increase in the concentration of LE in the range of $5-2500 \mu \mathrm{g} \mathrm{mL} \mathrm{m}^{-1}$, whereas ascorbic acid, as a standard antioxidant compound, displayed an increase in antioxidant activity from approximately $33 \%$ to $95 \%$. The $\mathrm{DPPH}^{*}$ radical scavenging effect increased with an increase in the concentration of the active compounds. The antioxidant activities of both LE and ascorbic acid were high in the concentration range between 20 and $2500 \mu \mathrm{g} \mathrm{mL}^{-1}$. Moreover, the half-maximum inhibitory concentration $\left(\mathrm{IC}_{50}\right)$ of $\mathrm{LE}$ was $8.90 \mu \mathrm{g} \mathrm{mL} \mathrm{mL}^{-1}$, which was close to that of the standard compound ascorbic acid $\left(\mathrm{IC}_{50}=6.76 \mu \mathrm{g} \mathrm{mL}{ }^{-1}\right)$. It has been reported that the polyphenolic compounds in LE have strong antioxidant activity, although this is slightly weaker than that of ascorbic acid. According to these results, LE might accelerate the healing of fractured bones by suppressing the inflammatory and destructive effects of free radicals on whole-body systems. ${ }^{21}$

The viability of NCTC clone 929 cells was determined using different concentrations of LE, and cell activity was measured using an REMA, ${ }^{22}$ as shown in ESI Fig. S2. $\dagger$ The results showed that the LE concentrations $\left(3.13-100 \mu \mathrm{g} \mathrm{mL}{ }^{-1}\right)$ used in this assay did not exhibit any cytotoxic effect on NCTC clone 929 cells. These results suggested that LE had no toxic effects on cell survival and growth.

\subsection{Gelation time of thermosensitive CS/ $\beta$-GP hydrogels}

In the CS/ $\beta$-GP system, the addition of $\beta$-GP, as a weak base, to an acidic CS solution neutralizes the system from a pH of 4.0 to a pH of 7.0, which is physiologically acceptable. Chenite et al. ${ }^{7}$ and Cho et al. ${ }^{23}$ found that the mechanisms of gelation in $\mathrm{CS} / \beta$ GP systems might be explained by the following factors: hydrogen bonding between CS chains, electrostatic interactions, and hydrophobic interactions involving the main molecular forces in gel formation. The several effective interactions responsible for the sol-to-gel transition can be briefly described as follows: (1) the addition of $\beta$-GP to a CS solution increases the ionic strength, which leads to a reduction in electrostatic repulsion between CS chains, and this can induce an increase in inter-chain hydrogen bonding in CS; (2) an electrostatic attraction occurs between the oppositely charged ammonium groups in CS and phosphate groups in $\beta$-GP; and (3) the hydrophobic or water-structuring character of the glycerol moiety in $\beta$-GP can enhance the hydrophobic interactions between CS molecules. In this study, the influences of the CS concentration and the volume ratio of CS to $\beta$-GP on the gelation time were studied. The gelation time of the thermosensitive $\mathrm{CS} / \beta$-GP hydrogels at $37^{\circ} \mathrm{C}$ was determined by a simple test tube inversion method. The hydrogel was a flowable viscous solution in the range of $4-25{ }^{\circ} \mathrm{C}$. After incubation at $37{ }^{\circ} \mathrm{C}$ for a period, a sol-gel transition was observed, and the hydrogel was transformed into a non-flowing gel. The gelation times of thermosensitive CS/ $\beta$-GP hydrogels prepared using different parameters are shown in Table 2. The concentration of CS in the range from $3.0 \%$ to $4.0 \%(\mathrm{w} / \mathrm{v})$ and the volume ratio of CS to $\beta$ GP (i.e., $0.7: 0.3,0.5: 0.5$ and $0.3: 0.7 \mathrm{~mL}$ ) had a strong effect on the gelation time. A volume ratio of $0.7: 0.3 \mathrm{~mL}$ of CS to $\beta$-GP in each set of conditions resulted in a prolonged gelation time; in particular, at a concentration of $3.0 \%(\mathrm{w} / \mathrm{v}) \mathrm{CS}$ a period of approximately $20 \mathrm{~h}$ was required to form a gel. In contrast, the addition of a large amount of $\beta$-GP caused the gelation time to decrease. A gel was formed within 10 min under the following conditions: a $3.0 \%(\mathrm{w} / \mathrm{v}) \mathrm{CS}$ solution at a CS: $\beta$-GP volume ratio of $0.3: 0.7 \mathrm{~mL}$, a $3.5 \%(\mathrm{w} / \mathrm{v})$ CS solution at a CS: $\beta$-GP volume ratio of $0.3: 0.7$ or $0.5: 0.5 \mathrm{~mL}$, and a $4.0 \%(\mathrm{w} / \mathrm{v})$ CS solution at a CS: $\beta$-GP volume ratio of $0.3: 0.7$ or $0.5: 0.5 \mathrm{~mL}$. Although a CS: $\beta$-GP volume ratio of $0.3: 0.7 \mathrm{~mL}$ at all CS concentrations resulted in a short gelation time, the hydrogels were deformed after gelation because of their high contents of $\beta$-GP. In the case of a $4.0 \%(\mathrm{w} / \mathrm{v}) \mathrm{CS}$ solution at a CS: $\beta$-GP volume ratio of $0.5: 0.5$ $\mathrm{mL}$, the hydrogel did not exhibit high fluidity because the solution had high viscosity, which resulted in difficulties with injection. Therefore, the optimal formulation comprised a 3.5\% $(w / v)$ CS solution and a CS: $\beta$-GP volume ratio of $0.5: 0.5 \mathrm{~mL}$.

The stability of the thermosensitive hydrogels at different $\mathrm{pH}$ values $(4,7$, and 10$)$ of the medium at $37^{\circ} \mathrm{C}$ is shown in Table S1. $\dagger$ The concentration of CS was fixed at $3.5 \%(\mathrm{w} / \mathrm{v})$, and the volume ratio of $\mathrm{CS}$ to $\beta$-GP was fixed at $0.5: 0.5 \mathrm{~mL}$. The results demonstrated that the thermosensitive CS/ $\beta$-GP hydrogels formed under all conditions were in a liquid form at room temperature and a gel form at $37^{\circ} \mathrm{C}$. The thermosensitive $\mathrm{CS} / \beta$ GP hydrogels at a $\mathrm{pH}$ of 4 exhibited a longer gelation time ( $\sim 32$ $\mathrm{min})$. However, an increase in the $\mathrm{pH}$ of the medium caused the gelation time to decrease. The gelation times of the thermosensitive CS/ $\beta$-GP hydrogels at $\mathrm{pH}$ value of 7 and 10 were $\sim 10 \mathrm{~min}$ and $\sim 5 \mathrm{~min}$, respectively. As the $\mathrm{pH}$ of the medium increased, the $\mathrm{pH}$ of the CS solution also increased. Thus, an increase in the $\mathrm{pH}$ of the hydrogel system caused the electrostatic interactions and hydrogen bonding between polymer chains to increase, which resulted in a decrease in the gelation time.

\subsection{Gelation time of thermosensitive $\mathbf{C S} / \mathrm{SS} / \boldsymbol{\beta}$-GP hydrogels}

The gelation times of the thermosensitive CS/SS/ $\beta$-GP hydrogels prepared using different SS concentrations are shown in Table 3. The gelation times of the thermosensitive $C S / S S / \beta-G P$ hydrogels were shorter than those of the CS/ $\beta$-GP hydrogels. The gelation time of the hydrogels displayed a decreasing trend with an increase in the SS concentration from $1.5 \%$ to $3.5 \%(\mathrm{w} / \mathrm{v})$. The reason might be that the SS molecules incorporated into the CS/ $\beta$-GP solution increased the attractive forces between neighboring macromolecular chains, which thereby reduced the gelation time. At a low temperature, hydrogen bonds were formed in the hydrogels between the amino groups of CS and SS, and SS also formed hydrogen bonds with water molecules. When the temperature was increased, the intermolecular hydrogen bonding interactions decreased. Therefore, the energized water molecules that surrounded the molecular chains were removed and the hydrophobic molecules in the CS and SS chains were highly entangled with each other. Thus, it was 
Table 2 Preparation parameters and gelation times of the thermosensitive CS/ $\beta$-GP hydrogels

\begin{tabular}{|c|c|c|c|}
\hline Concentration of CS $(\%, w / v)$ & $\mathrm{CS}: \beta-\mathrm{GP}(\mathrm{mL})$ & $\mathrm{pH}$ & Gelation time at $37^{\circ} \mathrm{C}(\mathrm{min})$ \\
\hline \multirow[t]{2}{*}{3.0} & $0.7: 0.3$ & $7.04 \pm 0.06$ & $1207.00 \pm 30.05$ \\
\hline & $0.5: 0.5$ & $7.57 \pm 0.00$ & $52.83 \pm 1.89$ \\
\hline \multirow[t]{3}{*}{3.5} & $0.7: 0.3$ & $7.24 \pm 0.01$ & $388.22 \pm 29.50^{a}$ \\
\hline & $0.5: 0.5$ & $7.64 \pm 0.01$ & $9.97 \pm 0.09^{a}$ \\
\hline & $0.3: 0.7$ & $7.88 \pm 0.05$ & $6.69 \pm 0.44$ \\
\hline & $0.3: 0.7$ & $8.14 \pm 0.01$ & $2.58 \pm 0.08^{a}$ \\
\hline
\end{tabular}

${ }^{a} p<0.05$ in comparison with the thermosensitive CS/ $\beta$-GP hydrogels prepared from a $3.0 \%(\mathrm{w} / \mathrm{v})$ solution of CS.

Table 3 Preparation parameters and gelation times of the thermosensitive CS/SS/ $\beta$-GP hydrogels

\begin{tabular}{|c|c|c|c|c|c|}
\hline $\mathrm{CS} / \beta-\mathrm{GP}$ & 3.5 & - & 50 & $0.5: 0.5$ & $9.97 \pm 0.09$ \\
\hline $\mathrm{CS} / \mathrm{SS} 1 / \beta-\mathrm{GP}$ & 3.5 & 1.5 & 50 & $0.5: 0.5$ & $6.91 \pm 0.08^{a}$ \\
\hline $\mathrm{CS} / \mathrm{SS} 3 / \beta-\mathrm{GP}$ & 3.5 & 3.5 & 50 & $0.5: 0.5$ & $5.59 \pm 0.24^{a}$ \\
\hline
\end{tabular}

${ }^{a} p<0.05$ in comparison with the thermosensitive CS/ $\beta$-GP hydrogels.

possible that the addition of SS to the CS/ $\beta$-GP hydrogel enhanced the hydrophobic interactions, which were the main driving force for the formation of a gel and the reduction in the time required for gel formation at a high temperature. Fig. 1 also confirms that the thermosensitive $\mathrm{CS} / \mathrm{SS} 3 / \beta$-GP hydrogels had thermosensitive properties at $37^{\circ} \mathrm{C}$ and did not revert to their original state at $25^{\circ} \mathrm{C}$.

\subsection{Rheological properties}

The effects of the gelation temperature of the thermosensitive $\mathrm{CS} / \beta$-GP and CS/SS/ $\beta$-GP hydrogels on the elastic (storage) modulus $\left(G^{\prime}\right)$ and viscous (loss) modulus $\left(G^{\prime \prime}\right)$ were determined using a rotational rheometer. When the temperature was increased from $20^{\circ} \mathrm{C}$ to $50{ }^{\circ} \mathrm{C}$, the hydrogels prepared under all conditions exhibited a rapid increase in the storage modulus $\left(G^{\prime}\right)$, which was explained by the phase transition from a sol to a gel around $35-39{ }^{\circ} \mathrm{C}$ (Fig. 2). The growth rate of the elastic modulus $\left(G^{\prime}\right)$ was higher than that of the viscous modulus $\left(G^{\prime \prime}\right)$ $\left(G^{\prime}>G^{\prime \prime}\right)$ beyond the gelling point, which indicates that the development of a gel structure contributed to an increase in the elasticity or gel strength of the hydrogels. ${ }^{24}$ The elastic modulus of the thermosensitive CS/ $\beta$-GP hydrogel exceeded $30 \mathrm{~Pa}$ at $45^{\circ} \mathrm{C}$ beyond the gelling point, but the elastic modulus of the thermosensitive $\mathrm{CS} / \mathrm{SS} / \beta$-GP hydrogels prepared under all conditions remained below $30 \mathrm{~Pa}$ at $45{ }^{\circ} \mathrm{C}$, whereas the thermosensitive $\mathrm{CS} / \mathrm{SS} / \beta$-GP hydrogels had lower strength, which might have been due to the weaker hydrophobic interactions between CS chains. Moreover, the crossover of the elastic modulus $\left(G^{\prime}\right)$ and the loss modulus $\left(G^{\prime \prime}\right)$ moved to a lower temperature, which indicates that the gelation temperature was reduced by the incorporation of SS. The crossover point (where $G^{\prime}$ and $G^{\prime \prime}$ are equal) of the thermosensitive CS/ $\beta$-GP hydrogel occurred at a higher temperature $\left(39^{\circ} \mathrm{C}\right)$ than that of the thermosensitive CS/SS/ $\beta$-GP hydrogels $\left(\sim 35-38^{\circ} \mathrm{C}\right)$. Because the SS
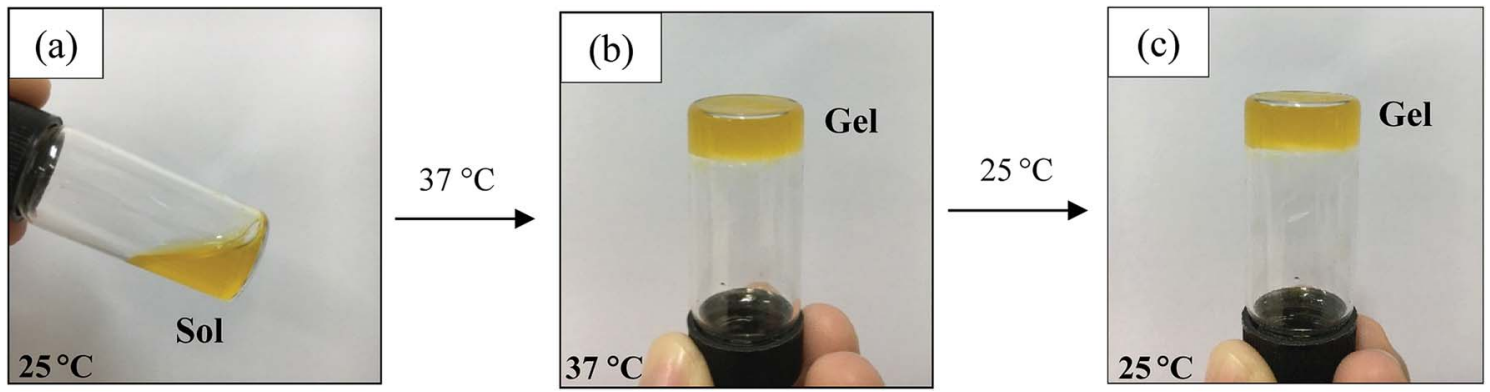

Fig. 1 Photographs of the sol-gel transition of a CS/SS3/ $\beta$-GP solution from a sol state at $25^{\circ} \mathrm{C}(\mathrm{a})$ to a gel state at $37^{\circ} \mathrm{C}(\mathrm{b})$ and the gel state at $25^{\circ} \mathrm{C}$ after the sol-gel transition (c). 
(a)

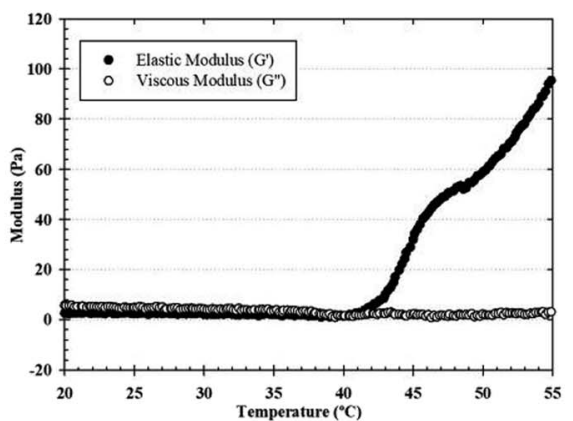

(c)

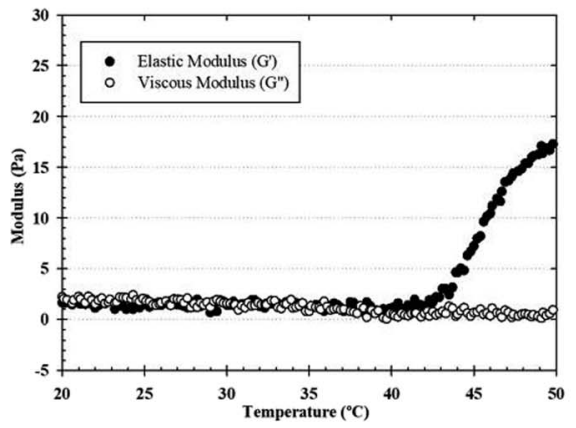

(b)

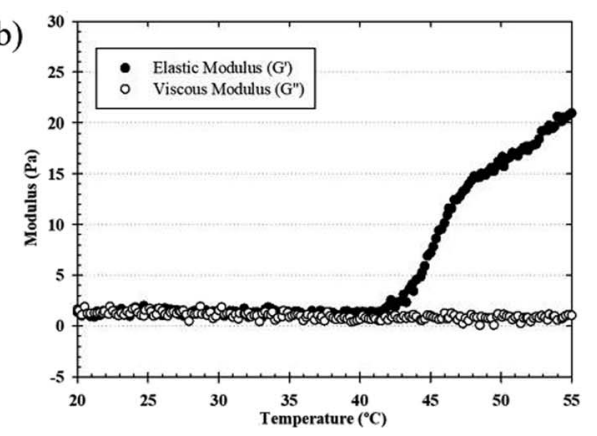

(d)

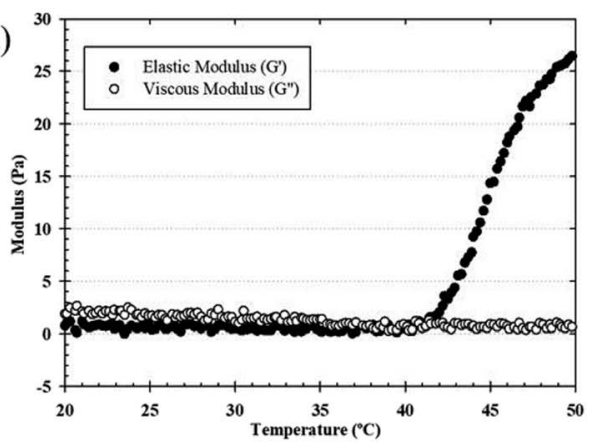

Fig. 2 Typical temperature dependence of $G^{\prime}$ and $G^{\prime \prime}$ values of the thermosensitive CS/ $\beta-G P(a), C S / S S 1 / \beta-G P(b), C S / S S 2 / \beta-G P(c)$ and CS/SS3/ $\beta-G P(d)$ hydrogels.

molecules incorporated into the CS/ $\beta$-GP solution caused the molecular interactions to increase, the gelation temperature was reduced. Hence, from these results it might be concluded that the addition of SS to the hydrogels had an effect on the gelation temperature.

\subsection{Viscosity measurements}

Injectable hydrogels based on thermosensitive polymers have interesting properties for tissue engineering. However, thermosensitive hydrogels should be strong enough to produce gels with sufficient stability for the proposed use. To prove the enhancement in the sol-gel transition behavior of the thermosensitive hydrogels, the values of the viscous modulus ( $\mathrm{Pa} \mathrm{s}$ ) of the thermosensitive $\mathrm{CS} / \beta-\mathrm{GP}$ and $\mathrm{CS} / \mathrm{SS} / \beta$-GP hydrogels were measured as a function of temperature. As shown in Fig. 3, the maximum value of the viscous modulus of the thermosensitive $\mathrm{CS} / \beta$-GP hydrogel was higher than those of the thermosensitive $\mathrm{CS} / \mathrm{SS} / \beta$-GP hydrogels prepared under all conditions. However, the phase transition temperature $\left(37^{\circ} \mathrm{C}\right)$ of the thermosensitive $\mathrm{CS} / \mathrm{SS} / \beta$-GP hydrogels prepared under all conditions was slightly lower than that of the thermosensitive CS/ $\beta$-GP hydrogel. These results indicated that the addition of SS to the hydrogels did not enhance their viscoelastic properties. This might be attributed to the expected electrostatic interaction between SS and CS chains. The electrostatic interactions of the amine $\left(-\mathrm{NH}_{2}\right)$ and hydroxyl $(-\mathrm{OH})$ groups in SS and the electron-rich oxygen atoms in the $-\mathrm{NH}_{2} /-\mathrm{OH}$ groups in CS caused a reduction in charge density on the CS chains. Because the number of charged ammonium groups on the CS chains was an important parameter that controlled the gelation of the system, the addition of SS to the hydrogels caused a decrease in their viscoelastic properties, which was due to a decline in the interaction between the ammonium groups in CS and the phosphate groups in $\beta$-GP.

\subsection{FTIR analysis}

FTIR spectroscopy was used to identify the interactions between the components of CS, SS, and $\beta$-GP. The FTIR spectra of the samples are shown in Fig. 4. All the samples exhibited broad absorption bands around 3600 and $3000 \mathrm{~cm}^{-1}$. These bands indicated the occurrence of $\mathrm{O}-\mathrm{H}$ stretching and $\mathrm{N}-\mathrm{H}$ stretching in the structures. The peaks in the range of $1685-1657 \mathrm{~cm}^{-1}$ were attributed to $\mathrm{C}=\mathrm{O}$ stretching in amide $\mathrm{I}$, and those at $1597-1459 \mathrm{~cm}^{-1}$ were assigned to $\mathrm{N}-\mathrm{H}$ bending in amide II in

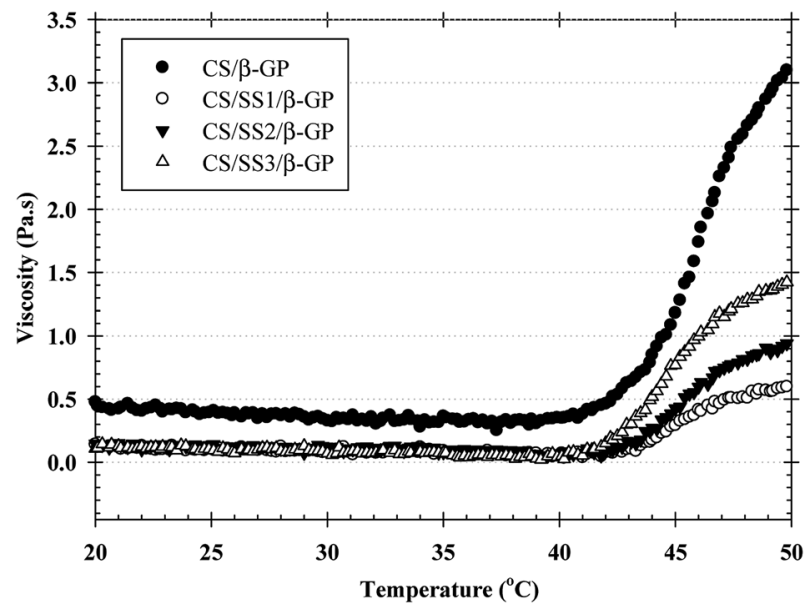

Fig. 3 Solution viscosity of the CS/ $\beta$-GP and $C S / S S / \beta-G P$ hydrogels as a function of temperature. 

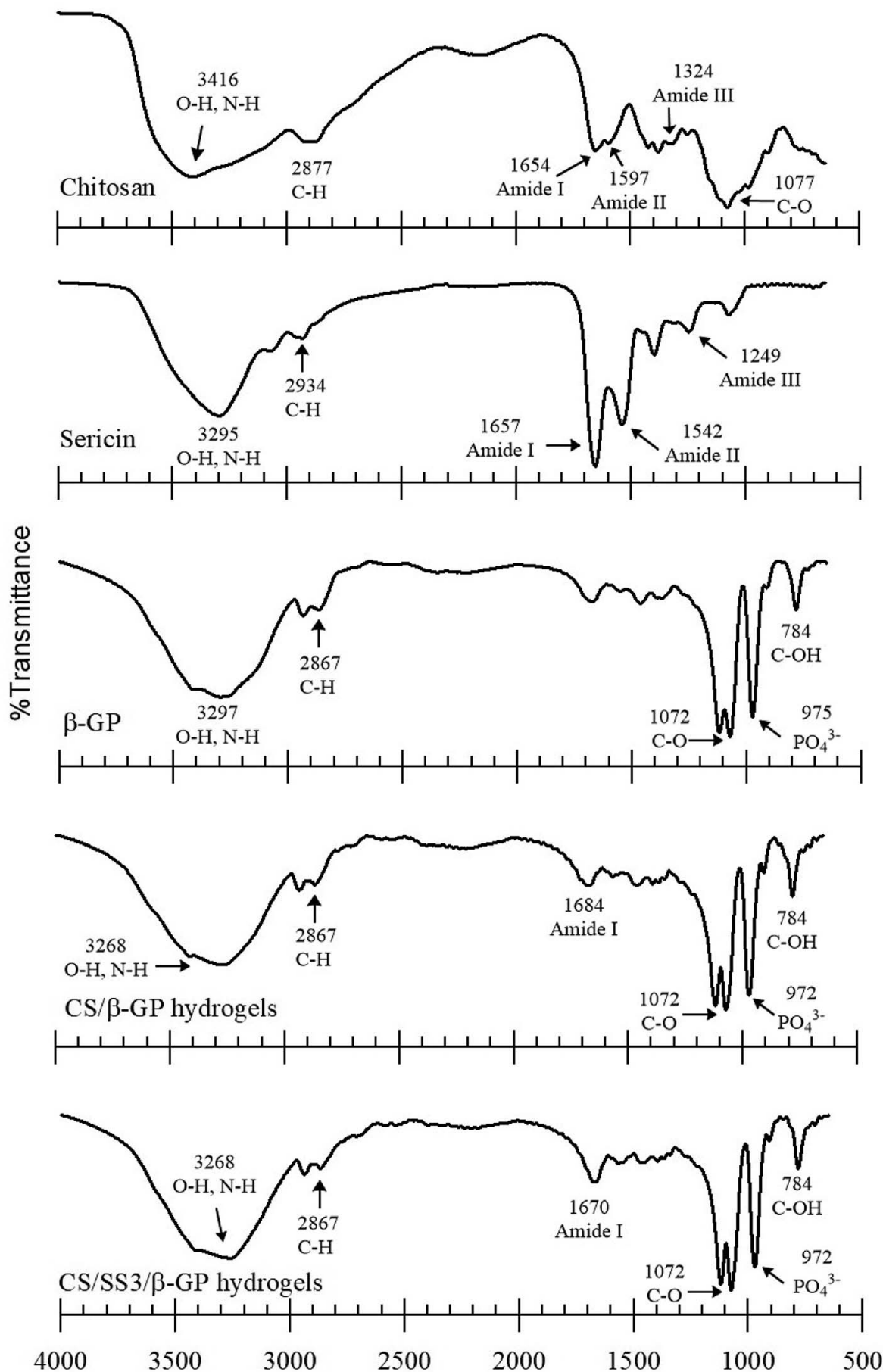

Wavenumber $\left(\mathrm{cm}^{-1}\right)$

Fig. 4 FTIR spectra of CS, SS, $\beta$-GP, CS/ $\beta$-GP hydrogel, and CS/SS3/ $\beta$-GP hydrogel.

CS and SS. Moreover, the spectra of CS and SS also displayed peaks at 1400-1200 $\mathrm{cm}^{-1}$, which were assigned to an in-phase combination of $\mathrm{N}-\mathrm{H}$ in-plane bending and $\mathrm{C}-\mathrm{N}$ stretching vibrations in amide III. ${ }^{25}$ In the case of the thermosensitive CS/ $\beta$-GP and CS/SS3/ $\beta$-GP hydrogels, the FTIR spectra displayed peaks at $3600-3000 \mathrm{~cm}^{-1}$, which indicated $\mathrm{O}-\mathrm{H}$ stretching. Peaks due to the inorganic phase of the $\mathrm{PO}_{4}{ }^{3-}$ groups were observed at 970 and $750 \mathrm{~cm}^{-1}$. The peaks due to $\mathrm{N}-\mathrm{H}$ and $\mathrm{O}-\mathrm{H}$ stretching in CS shifted after the formation of the gel. This might indicate bonding between $\mathrm{N}-\mathrm{H}$ groups in $\mathrm{CS}$ and $\mathrm{O}-\mathrm{H}$ groups in $\beta$-GP or hydrogen bonding between $\mathrm{C}=\mathrm{O}$ groups in $\mathrm{CS}$ and $\mathrm{O}-\mathrm{H}$ groups in $\beta$-GP. In addition, the peaks due to amides I, II and III in CS and SS decreased because hydrogen bonds and a chemical complex were formed between amino groups in $\mathrm{CS}$ or $\mathrm{SS}$ and $\mathrm{OH}$ and $\mathrm{PO}_{4}{ }^{3-}$ groups in $\beta$-GP. In addition, the peak due to $\mathrm{C}-\mathrm{CH}_{3}$ symmetric deformation 

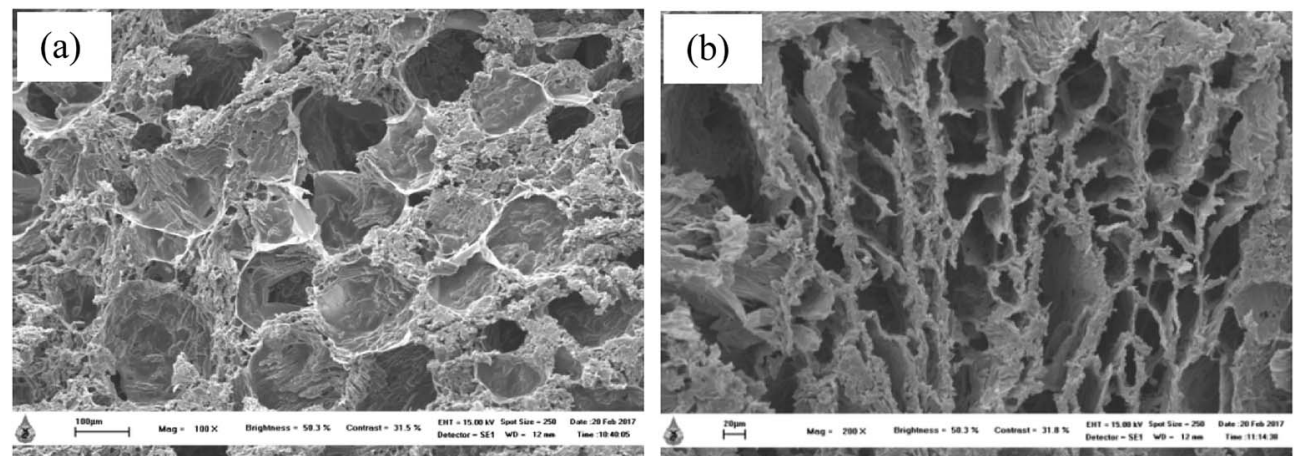

Fig. 5 SEM images of thermosensitive (a) CS/ $\beta$-GP (scale bar $=100 \mu \mathrm{m}$ ) and (b) CS/SS3/ $\beta$-GP (scale bar $=20 \mu \mathrm{m}$ ) hydrogels.

decreased in the spectra of the hydrogels, which indicated that $\mathrm{H}$ bonds might have been formed. Obviously, hydrogen bonding and electrostatic interactions existed between CS and $\beta-G P{ }^{26}$

\subsection{Scanning electron microscopy}

SEM images of thermosensitive $\mathrm{CS} / \beta-\mathrm{GP}$ and $\mathrm{CS} / \mathrm{SS} 3 / \beta-\mathrm{GP}$ hydrogels that were lyophilized at least $24 \mathrm{~h}$ before the observations are shown in Fig. 5. The morphological appearance of the thermosensitive $\mathrm{CS} / \beta$-GP hydrogel exhibited an irregular pore structure, whereas the morphological appearance of the $\mathrm{CS} / \mathrm{SS} / \beta$-GP hydrogel became more slender and porous. It has been reported that three-dimensional hydrogels with irregular porous structures can encourage the entrance of water or biological fluids into the hydrogel structures and support the diffusion of drugs out of the hydrogels. ${ }^{27}$

\subsection{Weight loss behavior of hydrogels}

The weight loss behavior of the thermosensitive CS/ $\beta$-GP and $\mathrm{CS} / \mathrm{SS} / \beta$-GP hydrogels was examined under simulated physiological conditions at $37{ }^{\circ} \mathrm{C}$. The weight loss of the

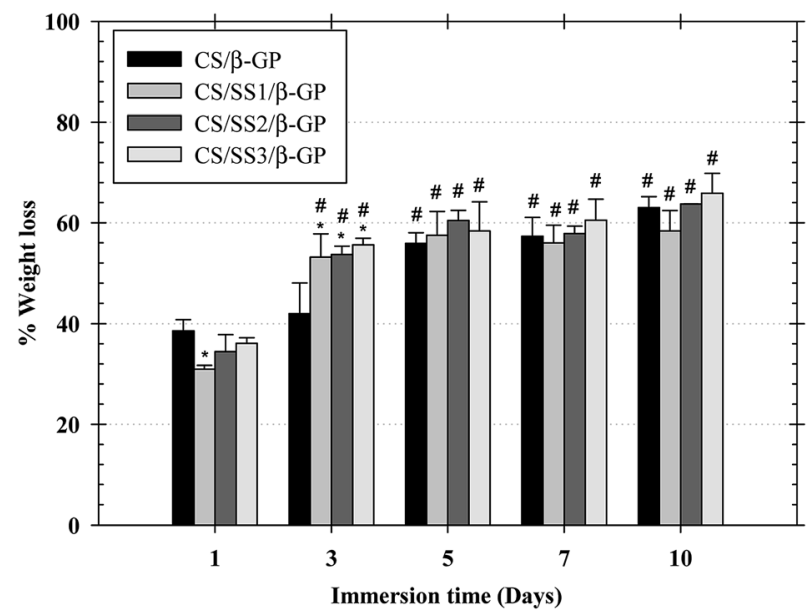

Fig. 6 Weight loss behavior of the thermosensitive CS/ $\beta$-GP and CS/ $\mathrm{SS} / \beta$-GP hydrogels in a PBS medium $(n=3) .{ }^{*} p<0.05$ in comparison with the thermosensitive CS/ $\beta$-GP hydrogel at any given time point, and ${ }^{*} p<0.05$ in comparison with an immersion time of 1 day for any given type of hydrogel. thermosensitive hydrogels in PBS (pH 7.4) after 1, 3, 5, 7, and 10 days is shown in Fig. 6. After 1 day, the weight loss of the thermosensitive $\mathrm{CS} / \beta-\mathrm{GP}, \mathrm{CS} / \mathrm{SS} 1 / \beta-\mathrm{GP}, \mathrm{CS} / \mathrm{SS} 2 / \beta-\mathrm{GP}$, and $\mathrm{CS} /$ SS3/ $\beta$-GP hydrogels was approximately $39 \%, 31 \%, 38 \%$, and $36 \%$, respectively, whereas after 3 days this value significantly increased to approximately $42 \%, 53 \%, 54 \%$, and $55 \%$, respectively. After 5 days, the value was approximately 56\%, 58\%, 60\%, and $58 \%$, respectively. After 7 days, the value was approximately

(a)

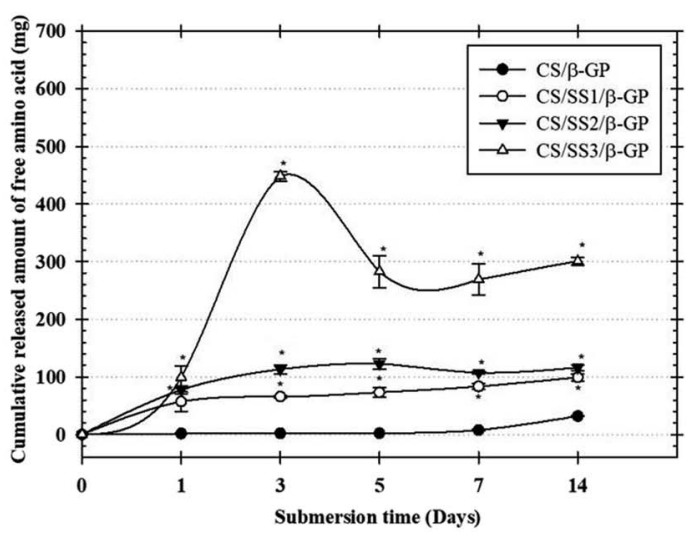

(b)

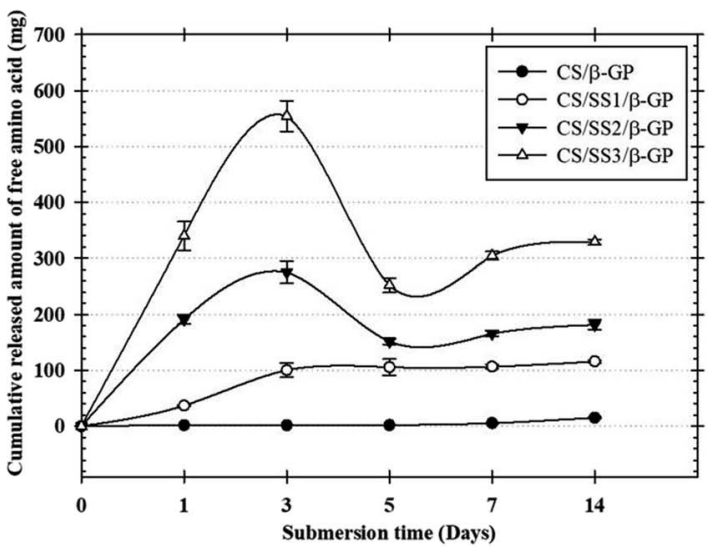

Fig. 7 In vitro degradation of the thermosensitive CS/ $\beta$-GP and CS/SS/ $\beta$-GP hydrogels in PBS (a) and PBS containing $\alpha$-amylase (b). The amounts of free amino groups were determined as a function of the degradation time by a ninhydrin assay at $570 \mathrm{~nm}(n=3)$. $* p<0.05 \mathrm{in}$ comparison with the thermosensitive CS/ $\beta$-GP hydrogels at a given time point. 
(a)

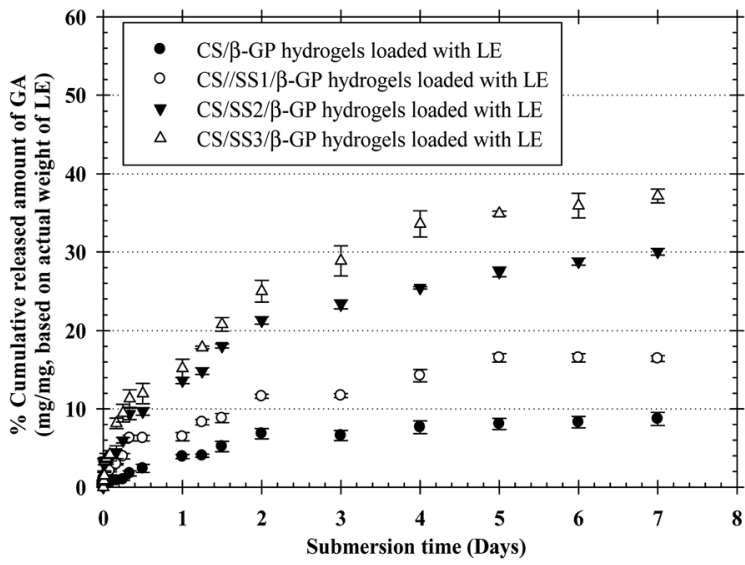

(b)

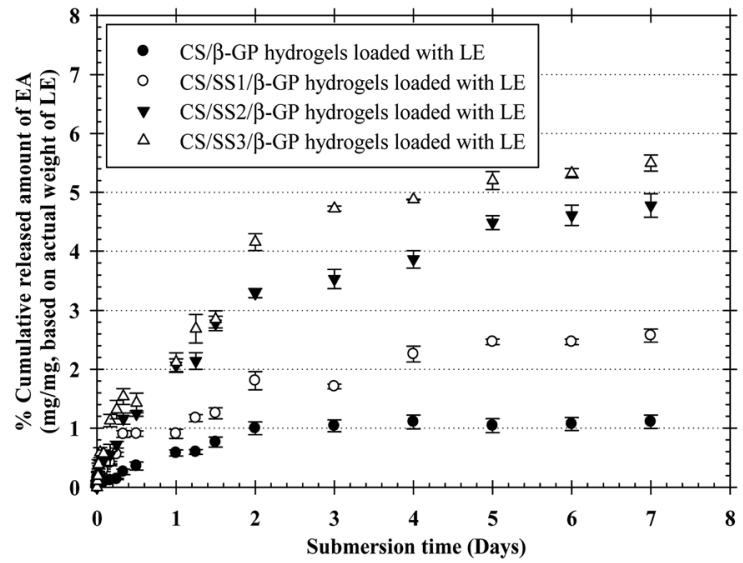

Fig. 8 Profiles of the cumulative release of GA (a) and EA (b) from the thermosensitive $C S / \beta-G P$ and $C S / S S / \beta-G P$ hydrogels loaded with LE reported as the percentage of the weight of GA or EA released divided by the actual weight of LE in the hydrogels and determined by total immersion in a PBS medium at $37^{\circ} \mathrm{C}(n=3)$.

$57 \%, 56 \%, 58 \%$, and $61 \%$, respectively. After 10 days, the value was approximately $63 \%, 58 \%, 64 \%$, and $66 \%$, respectively. According to these results, the weight loss of hydrogels prepared under all conditions was fairly high in the medium after an immersion time of 3 days and rather stable after an immersion time of 5-7 days. This indicated that water molecules diffused into the hydrogel rapidly during the initial 3 days and the maximum water absorption reached equilibrium after an immersion time of 3 days. In addition, the hydrogels containing SS exhibited a significantly higher weight loss after 3 days owing to the high water solubility of SS, which led to the breakup of polymer linkages and an increase in the degradation of the hydrogels. Therefore, the incorporation of SS affected the weight loss of these thermosensitive hydrogels and had the potential to enhance the availability of drugs at the desired site.

\subsection{In vitro degradation of hydrogels}

The in vitro degradation of the thermosensitive CS/ $\beta$-GP and CS/ $\mathrm{SS} / \beta$-GP hydrogels was investigated by measuring the loss of free amino groups in PBS ( $\mathrm{pH}$ 7.4) and PBS containing $\alpha$ amylase $(\mathrm{pH} 6.8)$ at $37{ }^{\circ} \mathrm{C}$. The amounts of free amino acid groups were measured by a ninhydrin assay. The cumulative amounts of free amino acids released from the hydrogels over a period of up to 2 weeks are presented in Fig. 7. The results showed that the thermosensitive CS/ $\beta$-GP hydrogel exhibited a lower degradation rate than those prepared under other conditions in both PBS and PBS containing $\alpha$-amylase. The incorporation of SS affected the network structure of the CS hydrogel, which caused it to degrade faster. These results suggested that SS might interfere with the polymeric network of CS and reduce the intermolecular interactions between CS and $\beta$ GP. Thus, water molecules might easily diffuse into the hydrogel matrix, which would lead to the loss of amino groups from the polymer chain. In addition, the morphological appearances of hydrogels with and without SS exhibited different pore structures. The difference in pore structure was due to the incorporation of SS into the thermosensitive CS/ $\beta$-GP hydrogels, as shown in Fig. 5. According to the results, the morphology of the thermosensitive $C S / \beta$-GP hydrogels exhibited a less porous structure, whereas the thermosensitive CS/SS/ $\beta$-GP hydrogels exhibited more porous structures at a high SS concentration.
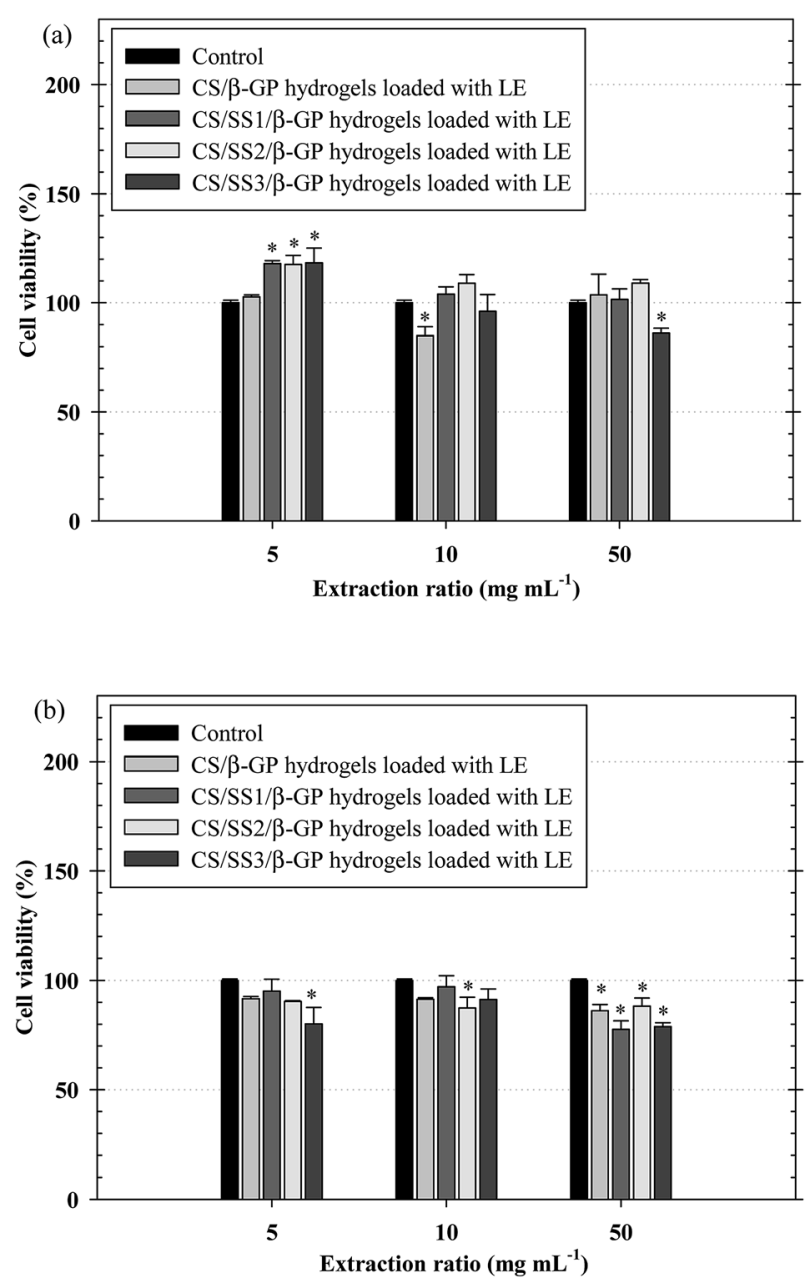

Fig. 9 Investigation of the indirect cytotoxicity of thermosensitive CS/ $\beta-G P$ and CS/SS/ $\beta$-GP hydrogels loaded with LE $(n=3)$ cultured with NCTC clone 929 (a) and MC3T3-E1 (b) cells. The viability of cells cultured with fresh SFM was used as a control. $* p<0.05$ in comparison with the control. 
Because the morphology of the materials plays a significant role in the degradation of hydrogels, the thermosensitive $\mathrm{CS} / \mathrm{SS} / \beta$ GP hydrogels with high porosity gave rise to a higher diffusion rate of water than those with low porosity. Thus, it can be concluded that the loss of free amino acid groups from the thermosensitive hydrogels was influenced by a combination of diffusion through pores and degradation of the polymer matrix.

\subsection{In vitro release of longan seed extract from hydrogels}

The profiles of the in vitro release of both GA and EA from the thermosensitive CS/ $\beta$-GP and CS/SS/ $\beta$-GP hydrogels loaded with LE were investigated as a function of time. Fig. 8 shows the profiles of the cumulative release of both GA and EA from the hydrogels over a period of 7 days. The profiles of the cumulative release of both drugs from all the hydrogels are presented in terms of the weight of the drug released (in $\mathrm{mg}$ ) divided by the actual weight of LE (in $\mathrm{mg}$ ). The results showed that the cumulative amounts of both drugs released from the thermosensitive CS/ $\beta$-GP hydrogels loaded with LE gradually increased during the first immersion period, increased more gradually afterward, and then reached a plateau during the longest immersion period. On the other hand, the cumulative amounts of both drugs released from the thermosensitive CS/SS/ $\beta$-GP hydrogels greatly increased during the first immersion time, increased substantially afterward, and then reached a plateau at the end of the observation period. Specifically, the maximum cumulative amounts of both GA and EA released from the thermosensitive $\mathrm{CS} / \mathrm{SS} 3 / \beta$-GP hydrogel were significantly higher than those released from the other hydrogels. Hence, the release of large amounts of phenolic compounds from the thermosensitive $\mathrm{CS} / \mathrm{SS} 3 / \beta$-GP hydrogel loaded with LE could promote the bone healing process. ${ }^{18,21}$ In addition, higher cumulative amounts of GA were released from these hydrogels after immersion in the medium in comparison with the released amounts of EA. This could be explained by the fact that GA has higher solubility in water than EA because EA contains four phenolic groups and two lactone groups, which result in poor water solubility. ${ }^{28}$ According to the results, the cumulative amounts of both drugs released from the thermosensitive CS/ $\beta$ GP hydrogel loaded with LE were lower than those released from the thermosensitive CS/SS/ $\beta$-GP hydrogels loaded with LE. These results suggested that SS might interfere with the polymeric network of CS and reduce the intermolecular interactions between CS and $\beta$-GP. Therefore, water molecules might easily diffuse into the hydrogel matrix, which would lead to the degradation of the hydrogel and an increase in the released amounts of drugs. Hence, the behavior of the drugs in terms of release from the hydrogels might be due to the degradation of the hydrogels, according to the results of in vitro degradation.

\subsection{Investigation of indirect cytotoxicity and cell attachment of hydrogels}

The biocompatibility of injectable polymeric biomaterials is an important consideration for bone tissue engineering, because the viability of cells should be maintained during gel formation. ${ }^{29} \mathrm{CS}$ is derived from a naturally occurring polymer and is known to be a biomaterial because of its ability to stimulate cell growth and interactions between cells and the extracellular matrix (ECM) ${ }^{30}$ Therefore, naturally derived biomaterials exhibit excellent biocompatibility, promote cell attachment and can support cell growth with high levels of viability and proliferation of cells. ${ }^{31}$ To evaluate the potential of the thermosensitive hydrogels loaded with LE for use in bone tissue engineering applications, an investigation of the indirect cytotoxicity of these hydrogels was carried out. The viability of NCTC clone 929 and MC3T3-E1 cells cultured with the extraction media from the
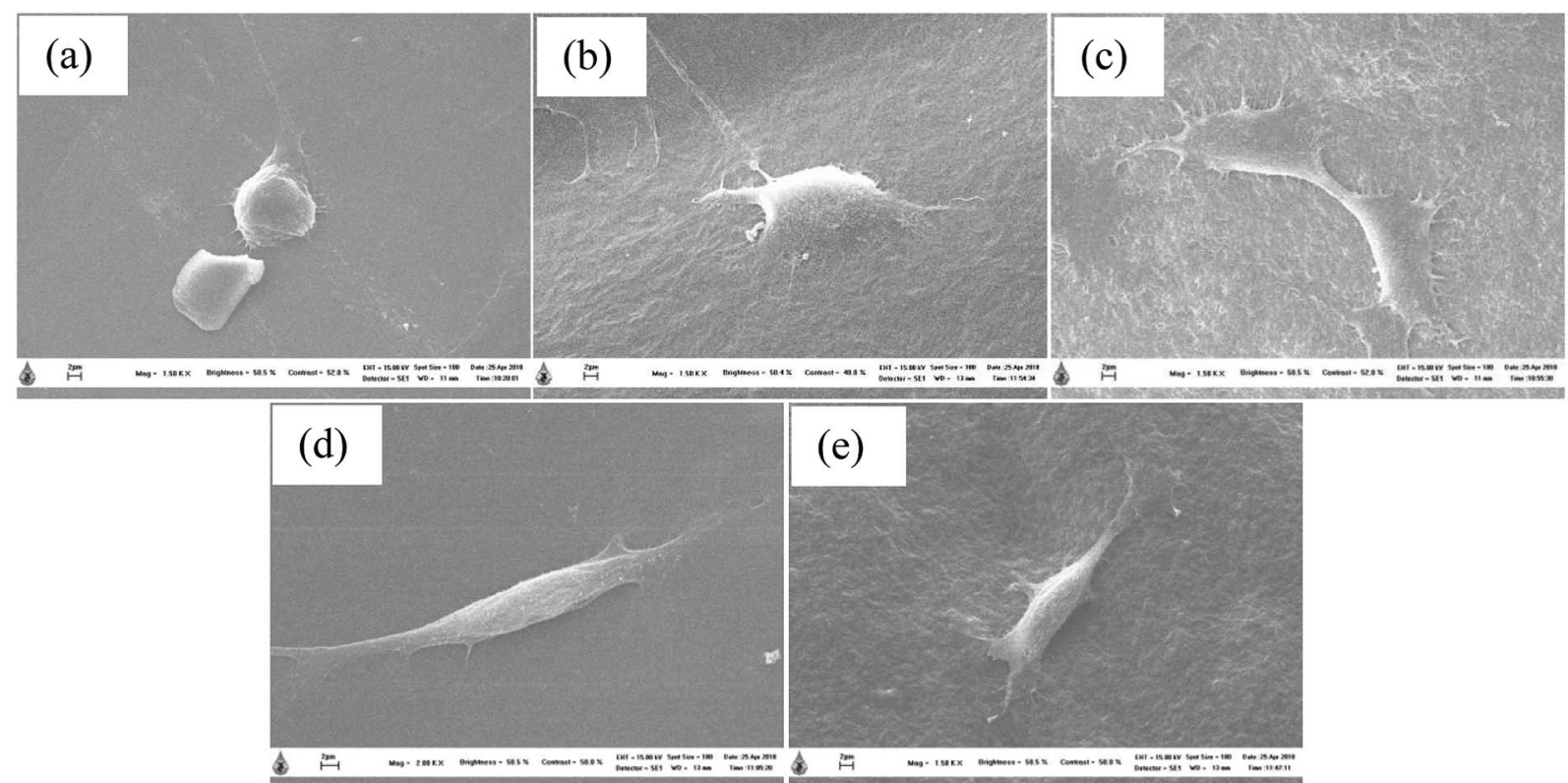

Fig. 10 Morphology and adhesion behavior of MC3T3-E1 cells on a cover glass (a), thermosensitive CS/ $\beta$-GP hydrogel without LE (b), CS/SS1/ $\beta$ GP hydrogel without LE (c), CS/ $\beta$-GP hydrogel loaded with LE (d), and CS/SS1/ $\beta$-GP hydrogel loaded with LE (e) after culture for $24 \mathrm{~h}$. 
hydrogels after incubation for $24 \mathrm{~h}$ was determined by an MTT assay, and the results are shown in Fig. 9. Clearly, the viability of NCTC clone 929 cells cultured with all the extraction media from all the thermosensitive hydrogels ranged between $\sim 86 \%$ and $\sim 118 \%$, whereas the viability of MC3T3-E1 cells ranged between $\sim 78 \%$ and $\sim 97 \%$. The ISO 10993-5 standard for in vitro cytotoxicity states that "reduction of cell viability by more than $30 \%$ is considered a cytotoxic effect". The viability of cells cultured with the extraction media from all the hydrogels was greater than $70 \%$ after treatment for $24 \mathrm{~h}$. These results indicated that these hydrogels were non-toxic to both NCTC clone 929 and MC3T3-E1 cells.

The morphology of MC3T3-E1 cells cultured on the thermosensitive hydrogels was observed by SEM. SEM images of attached MC3T3-E1 cells on the thermosensitive CS/ $\beta$-GP and CS/SS/ $\beta$-GP hydrogels loaded with LE and without LE in comparison with a cover glass used as a control after cell culture for $24 \mathrm{~h}$ are presented in Fig. 10. The results show that MC3T3E1 cells were attached to the cover glass and exhibited a round shape. However, the morphology of the attached MC3T3-E1 cells exhibited better adhesion and a flatter shape on the surfaces of all the thermosensitive hydrogels in comparison with the cover glass. Moreover, the attachment behavior of MC3T3-E1 cells exhibited a typical elongated and spindle-like morphology on the thermosensitive hydrogels loaded with LE. Therefore, the thermosensitive hydrogels loaded with LE have the potential for use in bone tissue engineering applications.

\section{Conclusions}

Injectable thermosensitive CS/ $\beta$-GP and CS/SS/ $\beta$-GP hydrogels loaded with LE were successfully fabricated for use in bone tissue engineering applications. The thermosensitive CS/ $\beta$-GP hydrogels were transformed from a sol into a gel at $37{ }^{\circ} \mathrm{C}$. Different ratios of CS to $\beta$-GP were employed to determine the optimal conditions for the preparation of the hydrogels. The optimal conditions comprised a $3.5 \%(\mathrm{w} / \mathrm{v}) \mathrm{CS}$ solution and a volume ratio of CS to $\beta$-GP of $0.5: 0.5 \mathrm{~mL}$. The incorporation of $\mathrm{SS}$ into the $\mathrm{CS} / \beta$-GP solution resulted in a shorter gelation time of 5-7 $\mathrm{min}$. The morphological structure of the thermosensitive CS/ $\beta$-GP hydrogel exhibited an irregular pore structure, whereas the thermosensitive $\mathrm{CS} / \mathrm{SS} / \beta$-GP hydrogels became more slender and porous. The weight loss of the thermosensitive $\mathrm{CS} / \beta$-GP and CS/SS/ $\beta$-GP hydrogels was greater than $50 \%$ after 3 days. The incorporation of SS affected the network structure of the CS hydrogels, which caused them to degrade more rapidly in both PBS and PBS containing $\alpha$ amylase. Moreover, the cumulative amounts of both GA and EA released from the thermosensitive hydrogels loaded with LE increased with an increase in the SS content. The fact that greater cumulative amounts of phenolic compounds were released from the thermosensitive CS/SS3/ $\beta$-GP hydrogel loaded with LE implies that this hydrogel has potential for the restoration of functional bone tissue. Finally, the thermosensitive hydrogels loaded with LE were non-toxic to both NCTC clone 929 and MC3T3-E1 cells and also promoted the attachment of MC3T3-E1 cells to the surface of materials. Hence, the thermosensitive hydrogels loaded with LE might be promising materials for use in bone tissue engineering applications.

\section{Conflicts of interest}

There are no conflicts to declare.

\section{Acknowledgements}

The authors would like to thank the Scientific and Technological Instruments Center (STIC) and Mae Fah Luang University. Porntipa Pankongadisak gratefully acknowledges the Royal Golden Jubilee PhD scholarship (PHD/0094/2558), Thailand Research Fund (TRF).

\section{References}

1 B. Jeong, S. W. Kim and Y. H. Bae, Thermosensitive sol-gel reversible hydrogels, Adv. Drug Delivery Rev., 2012, 64, 154.

2 C. Gong, T. Qi, X. Wei, Y. Qu, Q. Wu, F. Luo and Z. Qian, Thermosensitive polymeric hydrogels as drug delivery systems, Curr. Med. Chem., 2013, 20, 79.

3 L. Wang and J. P. Stegemann, Thermogelling chitosan and collagen composite hydrogels initiated with $\beta$ glycerophosphate for bone tissue engineering, Biomaterials, 2010, 31, 3976.

4 Z. Li, Z. Fan, Y. Xu, W. Lo, X. Wang, H. Niu, X. Li, X. Xie, M. Khan and J. Guan, $\mathrm{pH}$-sensitive and thermosensitive hydrogels as stem-cell carriers for cardiac therapy, ACS Appl. Mater. Interfaces, 2016, 8, 10752.

5 E. Ruel-Gariépy and J.-C. Leroux, In situ forming hydrogelsreview of temperature-sensitive systems, Eur. J. Pharm. Biopharm., 2004, 58, 409.

6 L. Liu, Q. Gao, X. Lu and H. Zhou, In situ forming hydrogels based on chitosan for drug delivery and tissue regeneration, Asian J. Pharm. Sci., 2016, 11, 673.

7 A. Chenite, C. Chaput, D. Wang, C. Combes, M. D. Buschmann, C. D. Hoemann, J. C. Leroux, B. L. Atkinson, F. Binette and A. Selmani, Novel injectable neutral solutions of chitosan form biodegradable gels in situ, Biomaterials, 2000, 21, 2155.

8 F. G. Tahrir, F. Ganji and T. M. Ahooyi, Injectable thermosensitive chitosan/glycerophosphate-based hydrogels for tissue engineering and drug delivery applications: a review, Recent Pat. Drug Delivery Formulation, 2015, 9, 107.

9 B. C. Dash, B. B. Mandal and S. C. Kundu, Silk gland sericin protein membranes: fabrication and characterization for potential biotechnological applications, J. Biotechnol., 2009, $144,321$.

10 N. Kato, S. Sato, A. Yamanaka, H. Yamada, N. Fuwa and M. Nomura, Silk protein, sericin, inhibits lipid peroxidation and tyrosinase activity, Biosci., Biotechnol., Biochem., 1998, 62, 145.

11 R. Rajendran, C. Balakumar, R. Sivakumar, T. Amruta and N. Devaki, Extraction and application of natural silk 
protein sericin from Bombyx mori as antimicrobial finish for cotton fabrics, J. Text. Inst., 2012, 103, 458.

12 Y. Tamada, M. Sano, K. Niwa, T. Imai and G. Yoshino, Sulfation of silk sericin and anticoagulant activity of sulfated sericin, J. Biomater. Sci., Polym. Ed., 2004, 15, 971.

13 Y. Q. Zhang, Applications of natural silk protein sericin in biomaterials, Biotechnol. Adv., 2002, 20, 91.

14 S. Kapoor and S. C. Kundu, Silk protein-based hydrogels: promising advanced materials for biomedical applications, Acta Biomater., 2016, 31, 17.

15 N. Rangkadilok, L. Worasuttayangkurn, R. N. Bennett and J. Satayavivad, Identification and quantification of polyphenolic compounds in Longan (Euphoria longana Lam.) fruit, J. Agric. Food Chem., 2005, 53, 1387.

16 Y. Y. Soong and P. J. Barlow, Isolation and structure elucidation of phenolic compounds from longan (Dimocarpus longan Lour.) seed by high-performance liquid chromatography-electrospray ionization mass spectrometry, J. Chromatogr. A, 2005, 1085, 270.

17 N. Rangkadilok, S. Sitthimonchai, L. Worasuttayangkurn, C. Mahidol, M. Ruchirawat and J. Satayavivad, Evaluation of free radical scavenging and antityrosinase activities of standardized longan fruit extract, Food Chem. Toxicol., 2007, 45, 328.

18 M. M. J. Al-Obaidi, F. H. Al-Bayaty, R. Al Batran, P. Hassandarvish and E. Rouhollahi, Protective effect of ellagic acid on healing alveolar bone after tooth extraction in rat-A histological and immunohistochemical study, Arch. Oral Biol., 2014, 59, 987.

19 G. Jiang, L. Wen, F. Chen, F. Wu, S. Lin, B. Yang and Y. Jiang, Structural characteristics and antioxidant activities of polysaccharides from longan seed, Carbohydr. Polym., 2013, 92, 758.

20 M. S. Blois, Antioxidant determinations by the use of a stable free radical, Nature, 1958, 181, 1199.

21 S. A. Sheweita and K. I. Khoshhal, Calcium metabolism and oxidative stress in bone fractures: role of antioxidants, Curr. Drug Metab., 2007, 8, 519.
22 J. O'Brien, I. Wilson, T. Orton and F. Pognan, Investigation of the alamar blue (resazurin) fluorescent dye for the assessment of mammalian cell cytotoxicity, Eur. J. Biochem., 2000, 267, 5421.

23 J. Cho, M.-C. Heuzey, A. Bégin and P. J. Carreau, Physical gelation of chitosan in the presence of $\beta$-glycerophosphate: the effect of temperature, Biomacromolecules, 2005, 6, 3267.

24 A. Chenite, M. Buschmann, D. Wang, C. Chaput and N. Kandani, Rheological characterization of thermogelling chitosan/glycerol-phosphate solutions, Carbohydr. Polym., 2001, 46, 39.

25 F. Mirahmadi, M. Tafazzoli-Shadpour, M. A. Shokrgozar and S. Bonakdar, Enhanced mechanical properties of thermosensitive chitosan hydrogel by silk fibers for cartilage tissue engineering, Mater. Sci. Eng., C, 2013, 33, 4786.

26 Z. Modrzejewska, K. Nawrotek, W. Maniukiewicz and T. Douglas, Structural characteristics of thermosensitive chitosan glutamate hydrogels in variety of physiological environments, J. Mol. Struct., 2014, 1074, 629.

27 E. P. Azevedo and V. Kumar, Rheological, water uptake and controlled release properties of a novel self-gelling aldehyde functionalized chitosan, Carbohydr. Polym., 2012, 90, 894.

28 I. Bala, V. Bhardwaj, S. Hariharan and M. N. V. Ravi Kumar, Analytical methods for assay of ellagic acid and its solubility studies, J. Pharm. Biomed. Anal., 2006, 40, 206.

29 B. Chang, N. Ahuja, C. Ma and X. Liu, Injectable scaffolds: preparation and application in dental and craniofacial regeneration, Mater. Sci. Eng., R, 2017, 111, 1.

30 I.-Y. Kim, S.-J. Seo, H.-S. Moon, M.-K. Yoo, I.-Y. Park, B.-C. Kim and C.-S. Cho, Chitosan and its derivatives for tissue engineering applications, Biotechnol. Adv., 2008, 26, 1.

31 F. J. O'Brien, Biomaterials \& scaffolds for tissue engineering, Mater. Today, 2011, 14, 88. 